\title{
Identifying "at-risk" patients for sub-optimal beta-lactam exposure in critically ill patients with severe infections
}

\author{
Mohd H. Abdul-Aziz ${ }^{1,2}$, Jeffrey Lipman ${ }^{1,3^{*}}$ and Jason A. Roberts ${ }^{1,3,4,5}$ \\ See related research by Ehmann et al., https://ccforum.biomedcentral.com/articles/10.1186/s13054-017-1829-4
}

Keywords: Augmented renal clearance, Critically ill, Meropenem, Pharmacokinetic, Pharmacodynamic, Risk assessment tool

\section{Pathophysiological changes affecting drug pharmacokinetics}

Mortality due to severe infections in the intensive care unit (ICU) remains high despite recent therapeutic advancements [1]. However, appropriate antibiotic administration (including spectrum of activity and therapeutic exposure) is rarely a straightforward process in ICU patients as they commonly develop extreme pathophysiological changes that can alter antibiotic pharmacokinetics and consequently affect drug exposure in this population. The volume of distribution and drug clearance are the pharmacokinetic parameters of greatest relevance to determining drug dosing requirements, and both parameters may be significantly deranged during critical illness $[2,3]$. Furthermore, ICU pathogens are relatively different from those in the general wards as they commonly have reduced antibiotic susceptibility [4]. Despite profound physiological and pharmacokinetic differences to the noncritically ill population, critically ill patients are typically given conventional antibiotic dosing regimens, which increase the likelihood of therapeutic failures and the emergence of bacterial resistance [5].

* Correspondence: j.lipman@uq.edu.au

${ }^{1}$ Faculty of Medicine, University of Queensland Centre for Clinical Research

(UQCCR), The University of Queensland, Building 71/918 Royal Brisbane \&

Women's Hospital, Brisbane, QLD 4029, Australia

${ }^{3}$ Department of Intensive Care Medicine, Royal Brisbane and Women's

Hospital, Brisbane, QLD, Australia

Full list of author information is available at the end of the article

\section{Optimal pharmacodynamic index for maximal beta-lactam activity}

Beta-lactam antibiotics display time-dependent pharmacodynamics, whereby the time for which the free (unbound) drug concentrations remain above the minimum inhibitory concentration $\left(f \Gamma_{>\text {MIC }}\right)$ best characterises bacterial killing [6]. Specifically, the $\% f \mathrm{~T}_{>\mathrm{MIC}}$ value needed for bactericidal activity is between 40 and $70 \%$ for these antibiotics. However, emerging clinical data from critically ill patients suggest that these patients may benefit from higher and longer antibiotic exposures $[7,8]$. It has since been suggested that beta-lactam concentrations should be maintained as at least four or five times the MIC for extended periods during each dosing interval (e.g. $90-100 \% \mathrm{~T}_{>4 \times \text { MIC }-5 \times \text { MIC }}$ ) to maximise patient outcomes, including suppressing the emergence of resistant bacteria [9]. Nevertheless, achieving this aggressive pharmacokinetic/pharmacodynamic target is not easy in critically ill patients, particularly when standard beta-lactam dosing is applied.

\section{Pharmacokinetic/pharmacodynamic derangements during critical illness}

The DALI study has reported significant variability in beta-lactam exposures in critically ill patients [5]. In this study, whilst plasma beta-lactam concentrations could vary by up to 500 -fold, pharmacokinetic/pharmacodynamic exposures varied by more than 1000-fold. Approximately one-fifth of the DALI cohort failed to achieve even the most conservative pharmacokinetic/pharmacodynamic target $\left(50 \% f \mathrm{~T}_{>\text {MIC }}\right)$ with standard beta-lactam dosing and these patients were $32 \%$ more likely to demonstrate negative outcomes (e.g. prolonged antibiotic courses). 
The complexity of beta-lactam dosing in critically ill patients has been characterised recently by Ehmann et al. [10] in their prospective, observational, single-centre pharmacokinetic study. In this study, 48 critically ill patients with severe sepsis were recruited, with the investigators evaluating the pharmacokinetic/pharmacodynamic target attainment of standard meropenem dosing (1000/2000 mg every 8 hours as a 30-min infusion) in critically ill patients. The investigators then developed a tool that may improve meropenem exposure in this population. Large variation in meropenem concentration was observed in this study, corroborating the findings of earlier studies $[2,5,11,12]$. The pharmacokinetic/pharmacodynamic target attainment of the cohort was relatively poor; only $56 \%$ and $48 \%$ of the cohort achieved the tested pharmacokinetic/pharmacodynamic targets of $50 \% f \mathrm{~T}_{>4 \times \mathrm{MIC}}$ and $100 \% f \mathrm{~T}_{>\mathrm{MIC}}$, respectively, against the MIC susceptibility breakpoint of $2 \mathrm{mg} / \mathrm{L}$. It is also noteworthy that the investigators had chosen to use two aggressive pharmacokinetic/pharmacodynamic targets as opposed to the conventional target for optimal betalactam activity $\left(50 \% f \mathrm{~T}_{>\mathrm{MIC}}\right)$. Furthermore, the MIC values were assumed from population estimates (EUCAST MIC breakpoints), inflating the magnitudes of target non-attainment in their analysis.

\section{Sub-therapeutic beta-lactam exposure and the in- fluence of renal function}

As the beta-lactams are predominantly cleared by the kidney, elevated renal function may likely lead to suboptimal antibiotic exposure, particularly when conventional dosing regimens are used [2, 13]. Patients with severe infections commonly develop a systemic inflammatory response syndrome, which increases renal blood flow and glomerular filtration rates. These factors enhance renal clearance of some drugs, a phenomenon referred to as augmented renal clearance (ARC). A measured creatinine clearance $\left(\mathrm{CL}_{\mathrm{CR}}\right) \geq 130 \mathrm{ml} / \mathrm{min}$ has been used to correlate ARC with sub-optimal antibiotic exposures [13]. Although ARC is highly prevalent in most ICUs [14], most clinicians fail to address the phenomenon, persisting with conventional beta-lactam dosing that is likely flawed, particularly when less susceptible pathogens are present.

In their study, Ehmann et al. [10] observed that increasing estimated $\mathrm{CL}_{\mathrm{CR}}$ significantly reduced the likelihood of pharmacokinetic/pharmacodynamic target attainment. This further highlights that those patients who are at risk for ARC, usually those with apparently "normal" renal function, have to be identified earlier so that dose modification can be made earlier $[2,13]$. In this respect, the investigators are certainly heading in the right direction with their proposed solution. They have developed a practical tool in commonly used software
(Microsoft Excel) to predict the risk of target nonattainment for non-RRT critically ill patients. This free and easy-to-use risk assessment tool, the MeroRisk Calculator, would be able to predict the likelihood of achieving $100 \% \mathrm{~T}_{>\text {MIC }}$ with standard meropenem dosing by inputting the $\mathrm{CL}_{\mathrm{CR}}$ of a patient or its determinants together with the MIC of a known or suspected pathogen. The calculated risk of target non-attainment is displayed with a three-colour coding system and at-risk patients are highlighted in red, which should prompt clinicians to alter dosing for such patients. Although the MeroRisk Calculator was developed based on a broad range of $\mathrm{CL}_{\mathrm{CR}}(25-255 \mathrm{ml} / \mathrm{min})$, the prediction uncertainty increases for the extremes of renal function due to the limited number of patients representing this subpopulation. The tool also provides a graphical illustration of the relationship between estimated $\mathrm{CL}_{\mathrm{CR}}$ and the predicted meropenem exposure which therefore describes the degree of uncertainty around their prediction.

This promising tool, however, can be improved upon. It was developed based on the Cockcroft-Gault $\mathrm{CL}_{\mathrm{CR}}$, but the measured $\mathrm{CL}_{\mathrm{CR}}$ is likely to be more appropriate in the ICU, particularly in patients with ARC [15]. Severity of illness may influence meropenem exposure, particularly in terms of the volume of distribution, and its impact should be incorporated into the Calculator. Actual MIC must be provided for accurate prediction as opposed to population estimates. The MeroRisk Calculator should be refined to also include other patient sub-groups, namely ECMO and RRT patients, in the prediction model.

\section{Conclusion}

Conventional beta-lactam dosing is flawed in critically ill patients. Useful tools such as the MeroRisk Calculator need to be comprehensively evaluated clinically, and if successful should be added into clinical practice to guide effective antibiotic dosing.

\section{Abbreviations \\ ARC: Augmented renal clearance; $\mathrm{CL}_{\mathrm{CR}}$ : Creatinine clearance; DALI: Defining Antibiotic Levels in Intensive care unit patients; ECMO: Extracorporeal membrane oxygenation; ICU: Intensive care unit; MIC: Minimum inhibitory concentration; RRT: Renal replacement therapy; $T_{>\text {MIc }}$ : Time for which drug concentration remains above the minimum inhibitory concentration during a dosing interval}

\section{Acknowledgements}

Not applicable.

\section{Funding}

JAR is funded by a Career Development Fellowship from the Australian National Health and Medical Research Council (APP1048652), the Australian National Health and Medical Research Council for a Centre of Research Excellence (APP1099452) and a Practitioner Fellowship (APP11117065).

Availability of data and materials Not applicable. 


\section{Authors' contributions}

MHA-A, JAR, and JL drafted the manuscript. MHA-A, JAR and JL critically revised the manuscript. All authors read and approved the final manuscript.

\section{Authors' information}

Not applicable.

\section{Ethics approval and consent to participate}

Not applicable.

\section{Consent for publication}

Not applicable.

\section{Competing interests}

The authors declare that they have no competing interests.

\section{Publisher's Note}

Springer Nature remains neutral with regard to jurisdictional claims in published maps and institutional affiliations.

\section{Author details}

${ }^{1}$ Faculty of Medicine, University of Queensland Centre for Clinical Research (UQCCR), The University of Queensland, Building 71/918 Royal Brisbane \& Women's Hospital, Brisbane, QLD 4029, Australia. ${ }^{2}$ School of Pharmacy, International Islamic University Malaysia, Kuantan, Malaysia. ${ }^{3}$ Department of Intensive Care Medicine, Royal Brisbane and Women's Hospital, Brisbane, QLD, Australia. ${ }^{4}$ Centre for Translational Anti-infective Pharmacodynamics, School of Pharmacy, The University of Queensland, Brisbane, QLD, Australia. ${ }^{5}$ Department of Pharmacy Royal Brisbane and Women's Hospital, Brisbane, QLD, Australia

\section{Received: 4 October 2017 Accepted: 24 October 2017}

\section{Published online: 21 November 2017}

\section{References}

1. Kaukonen KM, Bailey M, Suzuki S, Pilcher D, Bellomo R. Mortality related to severe sepsis and septic shock among critically ill patients in Australia and New Zealand, 2000-2012. JAMA. 2014;311(13):1308-16.

2. Huttner A, Von Dach E, Renzoni A, Huttner BD, Affaticati M, Pagani L, Daali Y, Pugin J, Karmime A, Fathi M, et al. Augmented renal clearance, low beta-lactam concentrations and clinical outcomes in the critically ill: an observational prospective cohort study. Int J Antimicrob Agents. 2015;45(4):385-92.

3. Goncalves-Pereira J, Povoa P. Antibiotics in critically ill patients: a systematic review of the pharmacokinetics of beta-lactams. Crit Care. 2011;15(5):R206.

4. Roberts JA, Abdul-Aziz MH, Lipman J, Mouton JW, Vinks AA, Felton TW, Hope WW, Farkas A, Neely MN, Schentag JJ, et al. Individualised antibiotic dosing for patients who are critically ill: challenges and potential solutions. Lancet Infect Dis. 2014;14(6):498-509.

5. Roberts JA, Paul SK, Akova M, Bassetti M, De Waele JJ, Dimopoulos G, Kaukonen KM, Koulenti D, Martin C, Montravers P, et al. DALI: defining antibiotic levels in intensive care unit patients: are current beta-lactam antibiotic doses sufficient for critically ill patients? Clin Infect Dis. 2014;58(8): 1072-83.

6. Craig WA. Pharmacokinetic/pharmacodynamic parameters: rationale for antibacterial dosing of mice and men. Clin Infect Dis. 1998;26(1):1-10. quiz $11-2$.

7. McKinnon PS, Paladino JA, Schentag JJ. Evaluation of area under the inhibitory curve (AUIC) and time above the minimum inhibitory concentration ( $\mathrm{T}>\mathrm{MIC}$ ) as predictors of outcome for cefepime and ceftazidime in serious bacterial infections. Int J Antimicrob Agents. 2008; 31(4):345-51.

8. Li C, Du X, Kuti JL, Nicolau DP. Clinical pharmacodynamics of meropenem in patients with lower respiratory tract infections. Antimicrob Agents Chemother. 2007:51(5):1725-30.

9. Abdul-Aziz MH, Lipman J, Mouton JW, Hope WW, Roberts JA. Applying pharmacokinetic/pharmacodynamic principles in critically ill patients: optimizing efficacy and reducing resistance development. Semin Respir Crit Care Med. 2015;36(1):136-53.

10. Ehmann L, Zoller M, Minichmayr IK, Scharf C, Maier B, Schmitt MV, Hartung N, Huisinga W, Vogeser M, Frey L, et al. Role of renal function in risk assessment of target non-attainment after standard dosing of meropenem in critically ill patients: a prospective observational study. Crit Care. 2017;21:263.

11. Tsai D, Stewart P, Goud R, Gourley S, Hewagama S, Krishnaswamy S, Wallis SC, Lipman J, Roberts JA. Optimising meropenem dosing in critically ill Australian Indigenous patients with severe sepsis. Int J Antimicrob Agents. 2016:48(5):542-6.

12. Mattioli F, Fucile C, Del Bono V, Marini V, Parisini A, Molin A, Zuccoli ML, Milano G, Danesi R, Marchese A, et al. Population pharmacokinetics and probability of target attainment of meropenem in critically ill patients. Eur J Clin Pharmacol. 2016;72(7):839-48.

13. Udy AA, Varghese JM, Altukroni M, Briscoe S, McWhinney BC, Ungerer JP Lipman J, Roberts JA. Subtherapeutic initial beta-lactam concentrations in select critically ill patients: association between augmented renal clearance and low trough drug concentrations. Chest. 2012;142(1):30-9.

14. Baptista JP, Udy AA, Sousa E, Pimentel J, Wang L, Roberts JA, Lipman J. A comparison of estimates of glomerular filtration in critically ill patients with augmented renal clearance. Crit Care. 2011;15(3):R139.

15. Carlier M, Dumoulin A, Janssen A, Picavet $S$, Vanthuyne $S$, Van Eynde $R$, Vanholder R, Delanghe J, De Schoenmakere G, De Waele JJ, et al. Comparison of different equations to assess glomerular filtration in critically ill patients. Intensive Care Med. 2015;41(3):427-35.

\section{Submit your next manuscript to BioMed Central and we will help you at every step:}

- We accept pre-submission inquiries

- Our selector tool helps you to find the most relevant journal

- We provide round the clock customer support

- Convenient online submission

- Thorough peer review

- Inclusion in PubMed and all major indexing services

- Maximum visibility for your research

Submit your manuscript at www.biomedcentral.com/submit 